Research, Society and Development, v. 7, n. 7, p. 01-22, e1177358, 2018

ISSN 2525-3409 (CC BY 4.0)

\title{
A formação do administrador para a docência: revisão sistemática da literatura
}

The administrator's training for teaching: systematic literature review

Maria Aldinete de Almeida Reinaldi

Universidade Estadual do Norte do Paraná, Brasil

E-mail: mariaaldinete@ hotmail.com

Annecy Tojeiro Giordani

Universidade Estadual do Norte do Paraná , Brasil

E-mail: annecy@uenp.edu.br

João Coelho Neto

Universidade Estadual do Norte do Paraná , Brasil

E-mail: joaocoelho@uenp.edu.br

Recebido: 18/04/2018 - Aceito: 26/04/2018

\section{Resumo}

O estudo objetiva revisar sistematicamente a literatura científica, acerca do processo de formação do administrador para a docência, considerando indícios de que muitos bacharéis em Administração atuam na área do Ensino, alguns deles sem domínio de competências e habilidades pedagógicas. A pesquisa foi feita no Instituto Brasileiro de Informação em Ciência e Tecnologia, no Banco de Teses e Dissertações da Coordenação de Aperfeiçoamento de Pessoal de Nível Superior do Ministério da Educação (CAPES/MEC), na Plataforma WebQualis e no Portal de Periódicos da CAPES/MEC. O intervalo de busca foi de 2010 a 2016 e foram selecionados 33 estudos. Os resultados indicam a possível omissão na formação pedagógica do administrador e também e a falta de políticas de formação continuada para aperfeiçoamento de suas práticas docentes. Desse modo, considera-se que, a formação docente é de extrema importância para o desenvolvimento e constituição do professor de Administração e, evidencia-se a valorização por parte dos professores, de uma formação pedagógica continuada que se apresenta como uma alternativa para a melhoria da prática docente nos cursos de Administração.

Palavras-chave: Formação docente; Administração; Revisão Sistemática de Literatura.

\footnotetext{
Abstract

The study aims to systematically review the scientific literature about the process of teacher training for the teachers, considering that many bachelors in Administration works in the
} 
Teaching area, some of them without mastery of pedagogical skills and abilities. The review was done in the Instituto Brasileiro de Informação em Ciência e Tecnologia, in the Thesis and Dissertation bank of the Coordenação de Aperfeiçoamento de Pessoal (CAPES), in the WebQualis Platform and in the CAPES periodicals portal. The search interval was from 2010 to 2016 and we selected 33 studies. The results indicate the possible omission in the administrator pedagogical training and also the lack of continuous training policies to improve their teaching practices. Thus, it is considered that, the teacher training is of extreme importance for the development and constitution of the Administration's teacher and, it is evident the appreciation by the teachers by a continuous pedagogical training that presents as an alternative for the improvement of the teaching practice in the Administration's courses.

Keywords: Teacher training; Administration; Systematic Literature Review

\section{Introdução}

Dadas as necessidades formativas atualmente exigidas dos profissionais bacharéis que atuam na docência, assim como, as habilidades e competências implicadas nesse processo, surge a preocupação com a formação do professor de Administração, pelo fato do seu Bacharelado não se voltar à formação de professores, mas de profissionais gestores de recursos de toda ordem, por meio do planejamento, organização, direção e controle, para o alcance dos objetivos de organizações de qualquer natureza (TAKEDA, 2011).

Segundo Soares et al. (2015), a Graduação em Administração proporciona ao aluno, formação que o capacita a atuar nas áreas administrativa, comercial, financeira, recursos humanos, logística, marketing e produção. Os conteúdos ensinados, também influem nas relações cotidianas, possibilitam ao administrador o desenvolvimento de habilidades e competências em diversas áreas do conhecimento e aprimoram a capacidade de tomar decisões, ter organização, planejamento, iniciativa, autoconfiança, desenvolver o espírito empreendedor e a habilidade para lidar com diversas situações práticas do ambiente empresarial.

As Diretrizes Curriculares Nacionais (DCN) do Curso de Graduação em Administração, determinam como essencial, o seguinte perfil do egresso:

[...] capacitação e aptidão para compreender as questões científicas, técnicas, sociais e econômicas da produção e de seu gerenciamento, observados níveis graduais do processo de tomada de decisão, bem como para desenvolver gerenciamento qualitativo e adequado, revelando a assimilação de novas informações e apresentando flexibilidade intelectual e adaptabilidade contextualizada no trato de situações diversas, presentes ou emergentes, nos vários segmentos do campo de atuação do administrador (BRASIL, 2005, p. 2). 
As características relacionadas acima trazem a preocupação com a formação docente nas instituições de Ensino Superior, considerando que a Resolução Normativa do Conselho Federal de Administração No 301, de 10 de Janeiro de 2005, determina em seu Art. $1^{\circ}$, que cabe ao administrador exercer o magistério das matérias técnicas dos campos da Administração e Organização, existentes nos currículos dos cursos de Graduação (Bacharelado), tanto em Administração como em currículos de cursos referentes a outros campos do conhecimento (BRASIL, 2005).

Por sua vez, a Lei de Diretrizes e Bases (LDB) de 1996, em seu artigo 52, inciso II, exige do profissional que atuará como professor de Administração, formação que seja adquirida prioritariamente em programas de pós-graduação nível stricto-sensu como o Mestrado e o Doutorado (BRASIL, 1996).

Para Torres (2010), existem brechas que relativizam o padrão de exigência de qualificação específica do corpo docente para cada área de atuação, considerando a LDB (BRASIL, 1996), em seu artigo 66, o qual determina que 1/3 do corpo docente de cada curso das Instituições de Ensino Superior (IES) deve ser composto por mestres e doutores. Em contrapartida, o Parecer MEC/CNE/CES nº 1.070 de 1999 exige esses títulos acadêmicos para apenas $1 / 3$ do corpo docente total das IES, “[...] As exigências referentes ao percentual de mestres e doutores e de docentes em regime de tempo integral aplicam-se, por analogia com as determinações da LDB, apenas à instituição no seu conjunto e não a um curso em particular" (BRASIL, 1999, p. 3).

Considerando a exigência formativa supracitada, Vieira (2014) destaca que os programas de pós-graduação stricto sensu, na sua maioria, enfocam a formação do pesquisador em detrimento da formação do professor, assim, não preparando o profissional para atuação docente.

Nesse sentido, Soares et al. (2015) resgatam que para lecionar no Ensino Médio ou Ensino Técnico, é suficiente que o profissional de administração seja apenas graduado, ou seja, tenha título de bacharel, licenciatura ou tecnólogo. Em contraposição, a esta exigência mínima, os autores consideram que a graduação não é suficiente para garantir o bom exercício docente e que o administrador, ao concluir a Graduação, não pode ser considerado um professor. Mesmo que tenha larga experiência profissional na administração, para lecionar é necessário saber lidar com as mais diversas situações dentro da sala de aula, o que requer domínio da didática, de processos de ensino e de aprendizagem, além do conhecimento em processos avaliativos. 
Research, Society and Development, v. 7, n. 7, p. 01-22, e1177358, 2018

ISSN 2525-3409 (CC BY 4.0)

Ao se levar em conta tais considerações, este estudo objetiva revisar sistematicamente a literatura científica acerca do processo de formação do administrador para a docência.

\section{2. $O$ administrador professor}

De acordo com Torres (2010), a formação do administrador professor pode estar ligada à uma prática gerencial, ao investimento pessoal em uma especialização e ao entendimento do senso comum que o desempenho em sala de aula é resultado de habilidade inata. No entanto, o exercício na docência tem demandado novas estratégias de ensino e preparação do administrador professor para enfrentar os desafios que se apresentam, visando à melhoria do ensino de Administração (OLIVEIRA; SOUERBRONN, 2007).

No tocante a identidade e a atividade do professor, autores como Delizoicov, Angotti e Pernambuco (2002, p. 14) argumentam que:

[...] se faz necessário ressignificar a identidade do professor. O ensino, atividade característica dele, é uma prática social complexa, carregada de conflitos de valores e que exige posturas éticas e políticas. Ser professor requer saberes e conhecimentos científicos, pedagógicos, educacionais, sensibilidade, indagação teórica e criatividade para encarar as situações ambíguas, incertas, conflituosas e, por vezes, violentas, presentes nos contextos escolares e não escolares.

Os mesmos autores, defendem a necessidade de se investir na formação e no desenvolvimento dos professores, dada sua importância nos processos transformadores das sociedades, o que justifica serem bem preparados, de modo que suas decisões pedagógicas e curriculares além de interessantes, possam se efetivar, gerando os efeitos desejados.

$\mathrm{Na}$ verdade, é inegável a grande necessidade de repensar, a formação para a docência, levando-se em conta os saberes dos professores e as realidades específicas do seu trabalho. Indica ainda, haver uma visão disciplinar e aplicacionista da formação profissional, que não tem mais sentido hoje em dia, não apenas no Ensino, mas também nos outros setores profissionais, sendo que: "Os sistemas escolares vêm-se hoje diante de exigências, expectativas e desafios sem precedentes e é no pessoal escolar e, mais especificamente nos professores, que essa situação crítica repercute com mais força” (TARDIF, 2014, p.114).

\section{Procedimentos metodológicos}

Pesquisa de cunho qualitativo, a qual segundo Marconi e Lakatos (2010), tem como premissa a analise e interpretação de aspectos mais profundos, descrevendo a complexidade 
do comportamento humano e, ainda, fornecendo análises mais detalhadas sobre as investigações, atitudes e tendências. Assim, os autores defendem que a ênfase da pesquisa qualitativa é nos processos e nos significados.

A Revisão Sistemática de Literatura (RSL), baseada em Kitchenham (2004), foi escolhida para o levantamentos dos estudos sobre a temática em questão, por se tratar de uma metodologia rigorosa, confiável e que permite auditoria, possibilitanto identificar, avaliar e interpretar todas as pesquisas relevantes, para então, responder a um foco de pesquisa específica. O processo compreende as três etapas: 1. Planejamento da revisão, 2. Execução e 3. Análise dos resultados.

Para o planejamento e desenvolvimento deste estudo, formulou-se as seguintes questões norteadoras: Na Graduação em Administração o aluno é preparado para o exercício da docência? Se sim, como ocorre esta preparação?

Para contemplar estes questionamentos, foi organizada uma revisão dos trabalhos publicados em quatro bancos de dados, sendo estes: 1 - Banco de teses e dissertações da Coordenação de Aperfeiçoamento de Pessoal de Nível Superior do Ministério de Educação (CAPES/MEC), 2. Instituto Brasileiro de Informação em Ciência e Tecnologia (IBICT), 3. Revistas listadas no índice restrito (A1, A2 e B1) nas áreas de Administração e que esteja também na área de Ensino, na Plataforma WebQualis e, 4. Portal de Periódicos da CAPES/MEC. O período de busca compreendeu de 2010 a 2016, seguido da quantificação e análise dos trabalhos consonantes com a formação docente e saberes em Administração.

O Quadro 1 mostra, resumidamente, os bancos de dados pesquisados, os critérios de inclusão e as quantidades de teses, dissertações e artigos encontrados.

\section{Quadro 1 - Síntese dos bancos de dados pesquisados, critérios de inclusão e resultados obtidos.}

\begin{tabular}{|c|c|c|}
\hline $\begin{array}{l}\text { Bancos de Dados } \\
\text { pesquisados }\end{array}$ & Critérios de inclusão & $\begin{array}{l}\text { Quantidade } \\
\text { de pesquisas }\end{array}$ \\
\hline $\begin{array}{l}\text { Banco de Teses e } \\
\text { Dissertações da } \\
\text { CAPES }\end{array}$ & $\begin{array}{l}\text { 1. Palavras-chave: Formação Docente; Administração. } \\
\text { 2. Período de busca: } 2010 \text { a 2016; } \\
\text { 3. Área de Avaliação: "Administração/Ciências Contábeis/Turismo" } \\
\text { e "Ciências Humanas"; } \\
\text { 4. Áreas de Conhecimento: "Administração" e "Educação"; } \\
\text { 5. Leitura dos títulos das pesquisas encontradas para identificação } \\
\text { das palavras-chave e seleção das pesquisas relacionadas ao tema } \\
\text { tratado. }\end{array}$ & $\begin{array}{c}3 \text { teses } \\
14 \text { dissertações }\end{array}$ \\
\hline $\begin{array}{l}\text { Instituto Brasileiro de } \\
\text { Informação em } \\
\text { Ciência e Tecnologia } \\
\text { IBICT }\end{array}$ & $\begin{array}{l}\text { 1. Opção de busca avançada, com as expressões: "Formação } \\
\text { docente" e "Administração". } \\
\text { 2. Período de busca: } 2010 \text { a 2016; } \\
\text { 3. Seleção de trabalhos em língua portuguesa. }\end{array}$ & $\begin{array}{c}2 \text { teses } \\
7 \text { dissertações }\end{array}$ \\
\hline $\begin{array}{l}\text { Plataforma WebQualis } \\
\text { CAPES }\end{array}$ & $\begin{array}{l}\text { 1. Evento de Classificação: "Qualificação de periódicos Quadriênio } \\
\text { 2013-2016"; }\end{array}$ & 6 artigos \\
\hline
\end{tabular}




\begin{tabular}{|c|l|l|}
\hline & 2. Áreas de Avaliação: "Ensino/Administração Pública/Ciências & \\
& Contábeis e Turismo"; & \\
& 3. Período de busca: 2010 a 2016; & \\
& 4. Estratificação: A1, A2 e B1; & \\
& $\begin{array}{l}\text { 5. Seleção de revistas em língua portuguesa; } \\
\text { 6. Leitura dos títulos das revistas para identificação do escopo } \\
\text { relacionado ao tema pesquisado. }\end{array}$ & \\
\hline Portal de Periódicos & $\begin{array}{l}\text { 1. Busca de artigos que contenham no título as palavras " Formação } \\
\text { de professores"; "Administração". }\end{array}$ & 1 artigo \\
CAPES & 2. Período: 2010 a 2016 & \\
\hline
\end{tabular}

Fonte: os autores

A pesquisa foi realizada no mês de julho de 2017, para a análise dos dados, utilizou-se a Análise Textual Discursiva (ATD), a qual possibilitou a construção de categorias apresentadas em Quadros. Para Moraes e Galiazzi (2007), a ATD constitui-se em uma metodologia de análise de dados de natureza qualitativa, que possibilita ao pesquisador desenvolver novas compreensões sobre os fenômenos e discursos no sentido de reconstrução num processo de movimento das verdades. Ainda, os autores a descrevem:

[...] como um processo auto-organizado de construção de compreensão em que novos entendimentos emergem de uma sequencia recursiva de três componentes: a desconstrução dos textos do "corpus", a unitarização; estabelecimento de relações entre os elementos unitários, a categorização; o captar o emergente em que a nova compreensão é comunicada e validada (MORAES; GALIAZZI, 2007, p.12).

As categorias na ATD podem ser produzidas por diferentes metodologias. O método dedutivo implica construir categorias antes mesmo de examinar o "corpus", que é o conjunto de documentos a ser analisado. Neste método, as categorias são deduzidas das teorias que servem de fundamento para a pesquisa $e$ constituem as categorias a priori (MORAES; GALIAZZI, 2007). Esse método foi utilizado na criação da primeira categoria: Processos formativos e a constituição de Administradores. Por sua vez, o método indutivo implica construir as categorias com base nas informações do corpus, quando o pesquisador vai organizando conjuntos de elementos semelhantes e que resultam nas categorias emergentes (MORAES; GALIAZZI, 2007, p. 23). Esse método foi utilizado para a criação a posteriori da segunda categoria: Docência em Administração e conhecimentos pedagógicos.

\section{Resultados}

A primeira busca no Banco de Teses e Dissertações da CAPES, fez um mapeamento das produções que contemplam a questão norteadora desta pesquisa, tendo-se utilizado as palavras-chave "Formação Docente" e “ Administração", o que resultou em 187.549 trabalhos. A partir do comando "Refinar meus resultados" foi incluído o período de busca de 2010 a 2016, a área de Avaliação “Administração/Ciências Contábeis/Turismo" e “ Ciências 
Humanas", seguida da área de Conhecimento "Administração" e "Educação", o que resultou em 9.506 trabalhos.

Foi realizada a leitura do título de cada trabalho para identificação e seleção daqueles com as palavras-chave "Docência em Administração e formação de professores". Aqueles que não tratavam da temática em questão e que não faziam uso de uma ou mais palavras-chave, foram excluídos da análise. Sendo assim, a utilização dos critérios pré-estabelecidos, resultou em um total de 17 pesquisas de Pós-graduação stricto sensu, sendo 14 dissertações de Mestrado e 3 teses de Doutorado. O Quadro 2 apresenta uma síntese das pesquisas selecionadas, com as informações referentes ao título da pesquisa, autor, tipo de trabalho acadêmico, ano da defesa, programas/IES e área de conhecimento.

Quadro 2 - Síntese dos trabalhos selecionados sobre formação docente em Administração, segundo o título da pesquisa, autor, tipo de trabalho acadêmico, ano da defesa, programa/IES e área de conhecimento.

\begin{tabular}{|c|c|c|c|c|c|c|}
\hline $\mathbf{N}$ & Título & Autor (a) & Tipo & Ano & Programa/IES & $\begin{array}{c}\text { Área de } \\
\text { conhecimento }\end{array}$ \\
\hline 1 & $\begin{array}{l}\text { Trabalho e Formação } \\
\text { Docente em Tempos Globais } \\
\text { e a Constituição de } \\
\text { Administradores Professores }\end{array}$ & $\begin{array}{ll}\text { Valéria } & \text { de } \\
\text { Araújo } & \\
\text { Torres } & \end{array}$ & Dissertação & 2010 & $\begin{array}{l}\text { Universidade de } \\
\text { Uberaba. }\end{array}$ & Educação \\
\hline 2 & $\begin{array}{l}\text { Formação de Formadores: } \\
\text { Uma Experiência no Curso } \\
\text { de Administração na } \\
\text { Modalidade a Distância }\end{array}$ & $\begin{array}{l}\text { Vanessa de } \\
\text { Carvalho } \\
\text { Forte }\end{array}$ & Dissertação & 2010 & $\begin{array}{l}\text { Universidade } \\
\text { Estadual do } \\
\text { Ceará- Fortaleza }\end{array}$ & Educação \\
\hline 3 & $\begin{array}{lr}\text { Narrativas sobre } & \text { Prática } \\
\text { Pedagógica } & \text { e } \\
\text { desenvolvimento } & \\
\text { profissional: } & \\
\text { Administradores-professores } \\
\text { de ensino superior como } \\
\text { protagonistas. }\end{array}$ & $\begin{array}{l}\text { Shirlei } \\
\text { Dourado } \\
\text { Rebêlo } \\
\text { Saraiva }\end{array}$ & Dissertação & 2010 & $\begin{array}{l}\text { PPG-Fundação } \\
\text { Universidade } \\
\text { Federal do Piauí }\end{array}$ & Administração \\
\hline 4 & $\begin{array}{l}\text { Demandas e Competências } \\
\text { nas Práticas Docentes no } \\
\text { curso de Administração de } \\
\text { Empresas - Bacharelado. }\end{array}$ & $\begin{array}{l}\text { Sergio Luiz } \\
\text { Conti }\end{array}$ & Dissertação & 2010 & $\begin{array}{l}\text { PPG- } \\
\text { Universidade de } \\
\text { São Paulo }\end{array}$ & Educação \\
\hline 5 & $\begin{array}{l}\text { A Formação em } \\
\text { Administração: A Visão e as } \\
\text { Práticas Pedagógicas em IES } \\
\text { de Excelência do Rio de } \\
\text { Janeiro }\end{array}$ & $\begin{array}{l}\text { Alexandre } \\
\text { Fernandes } \\
\text { Ferreira }\end{array}$ & Dissertação & 2010 & $\begin{array}{l}\text { PPG-Fundação } \\
\text { Getúlio Vargas- } \\
\text { RJ }\end{array}$ & Administração \\
\hline 6 & $\begin{array}{l}\text { A Formação em } \\
\text { Administração: A Visão e as } \\
\text { Práticas Pedagógicas em IES } \\
\text { de Excelência do Rio de } \\
\text { Janeiro }\end{array}$ & $\begin{array}{l}\text { Alexandre } \\
\text { Fernandes } \\
\text { Ferreira }\end{array}$ & Dissertação & 2010 & $\begin{array}{l}\text { PPG-Fundação } \\
\text { Getúlio Vargas- } \\
\text { RJ }\end{array}$ & Administração \\
\hline 7 & $\begin{array}{l}\text { Dormi Profissional, Acordei } \\
\text { Professor: um Estudo sobre } \\
\text { a Prática Pedagógica do } \\
\text { Docente do Curso de } \\
\text { Administração da UNIPAR - } \\
\text { Paraná/ Brasil } \\
\end{array}$ & $\begin{array}{l}\text { Sirlene } \\
\text { Aparecida } \\
\text { Takeda }\end{array}$ & Dissertação & 2011 & $\begin{array}{l}\text { Universidade do } \\
\text { Sul de Santa } \\
\text { Catarina }\end{array}$ & Educação \\
\hline
\end{tabular}


ISSN 2525-3409 (CC BY 4.0)

\begin{tabular}{|c|c|c|c|c|c|c|}
\hline 8 & $\begin{array}{l}\text { Desafios da formação } \\
\text { docente: Estágio Docência e } \\
\text { a prática de ensino em } \\
\text { administração }\end{array}$ & $\begin{array}{l}\text { Nathália de } \\
\text { Fátima } \\
\text { Joaquim }\end{array}$ & Dissertação & 2011 & $\begin{array}{l}\text { Universidade } \\
\text { Federal de } \\
\text { Lavras }\end{array}$ & Administração \\
\hline 9 & $\begin{array}{l}\text { A Inserção da noção de } \\
\text { competências na prática } \\
\text { docente: um estudo em curso } \\
\text { de graduação } \\
\text { Administração } \\
\end{array}$ & $\begin{array}{l}\text { Laci } \\
\text { Siqueira }\end{array}$ & Dissertação & 2011 & $\begin{array}{l}\text { PPG- Pontifícia } \\
\text { Universidade } \\
\text { Católica de } \\
\text { Minas Gerais }\end{array}$ & Administração \\
\hline 10 & $\begin{array}{l}\text { Mapeamento de } \\
\text { Competências Docentes: } \\
\text { Estudo entre Acadêmicos de } \\
\text { Administração } \\
\end{array}$ & $\begin{array}{l}\text { Marcio } \\
\text { Sampedro } \\
\text { Ramos }\end{array}$ & Dissertação & 2011 & $\begin{array}{l}\text { PPG- } \\
\text { Universidade } \\
\text { Federal de Santa } \\
\text { Maria } \\
\end{array}$ & Administração \\
\hline 11 & $\begin{array}{l}\text { Formaçãa docente } \\
\text { inovaçôes tecnológicas de } \\
\text { informação e comunicação: } \\
\text { um estudo do curso de } \\
\text { Administração }\end{array}$ & $\begin{array}{l}\text { Thais Rubia } \\
\text { Ferreira }\end{array}$ & Dissertação & 2012 & $\begin{array}{l}\text { Universidade do } \\
\text { Oeste Paulista - } \\
\text { Presidente } \\
\text { Prudente. }\end{array}$ & Educação \\
\hline 12 & $\begin{array}{l}\text { Professor Universitário dos } \\
\text { Cursos de Administração e } \\
\text { Ciências Contábeis: Saberes } \\
\text { e Práticas. }\end{array}$ & $\begin{array}{l}\text { Geraldo } \\
\text { Rodrigues } \\
\text { da Silva }\end{array}$ & Diss & 2012 & $\begin{array}{l}\text { Universidade } \\
\text { Católica de } \\
\text { Santos. }\end{array}$ & ducação \\
\hline 13 & $\begin{array}{l}\text { Da Formação á Docência: } \\
\text { um estudo em IESs } \\
\text { mineiras. }\end{array}$ & $\begin{array}{l}\text { Cassio } \\
\text { Raimundo } \\
\text { Valdisser }\end{array}$ & Disse & 2012 & $\begin{array}{l}\text { Universidade } \\
\text { Federal de } \\
\text { Uberlândia } \\
\end{array}$ & istração \\
\hline 14 & 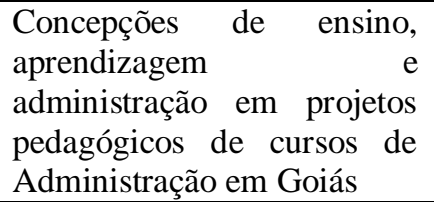 & $\begin{array}{l}\text { Jhonny } \\
\text { Afonso } \\
\text { Cunha }\end{array}$ & Dissertação & 2012 & $\begin{array}{l}\text { PPG- Pontifícia } \\
\text { Universidade } \\
\text { Católica de } \\
\text { Goiás }\end{array}$ & Educação \\
\hline 15 & $\begin{array}{l}\text { Competências profissionais } \\
\text { do professor do ensino } \\
\text { superior para lecionar } \\
\text { administração, rór } \\
\text { graduação lato sensu, na } \\
\text { EAD on line: um estudo em } \\
\text { IES da r Região } \\
\text { Metropolitana do Recife }\end{array}$ & $\begin{array}{l}\text { Rita de } \\
\text { Cássia Braga } \\
\text { de Melo }\end{array}$ & Dissertação & 2012 & $\begin{array}{l}\text { PPG- } \\
\text { Universidade } \\
\text { Federal de } \\
\text { Pernambuco }\end{array}$ & Administração \\
\hline 16 & $\begin{array}{lr}\text { Os saberes } & \text { docentes } \\
\text { construídos } & \text { pelos } \\
\text { professores e as práticas de } \\
\text { ensino no Curso Superior de } \\
\text { Administração } \\
\text { FCAP/UPE }\end{array}$ & $\begin{array}{l}\text { Arandi } \\
\text { Maciel } \\
\text { Campelo }\end{array}$ & Tese & 2011 & $\begin{array}{l}\text { Universidade } \\
\text { Federal de } \\
\text { Pernambuco, } \\
\text { Recife }\end{array}$ & Educação \\
\hline 17 & $\begin{array}{l}\text { O processo de socialização } \\
\text { profissional de professores } \\
\text { do ensino superior atuantes } \\
\text { no curso de administração: } \\
\text { trajetórias, saberes e } \\
\text { identidades. }\end{array}$ & $\begin{array}{l}\text { Marciano de } \\
\text { Almeida } \\
\text { Cunha }\end{array}$ & Tese & 2011 & $\begin{array}{l}\text { Pontifícia } \\
\text { Universidade } \\
\text { Católica de São } \\
\text { Paulo. }\end{array}$ & Educação: \\
\hline 18 & $\begin{array}{l}\text { Gestão eficiente em sala de } \\
\text { aula: seis estudos em } \\
\text { ciências sociais aplicadas. }\end{array}$ & $\begin{array}{l}\text { Waldemar } \\
\text { Hazoff } \\
\text { Júnior }\end{array}$ & Tese & 2012 & $\begin{array}{l}\text { PPG- } \\
\text { Universidade de } \\
\text { São Paulo }\end{array}$ & Administração \\
\hline
\end{tabular}

\section{Fonte: Os autores}

A segunda busca foi realizada no site de teses e dissertações do IBICT, tendo-se utilizado a opção de busca avançada com inserção das palavras-chave: "Formação docente" e “Administração", período de 2010 a 2016 e idioma português, o que resultou em 184 
trabalhos. Após aplicados os mesmos critérios de exclusão da pesquisa no banco de dados supracitado e leitura minuciosa dos títulos, somente 9 trabalhos, sendo 7 dissertações e 2 teses foram disponibilizadas, 4 na área de Administração e 5 na área de Educação.

O Quadro 3, apresenta resumidamente os trabalhos selecionados no IBICT, relacionados por títulos, autores, tipo, ano, programa/IES e área de conhecimento.

Quadro 3 - Síntese dos trabalhos selecionados no IBICT, sobre formação docente em Administração, segundo o título da pesquisa, autor, tipo de trabalho acadêmico, ano da defesa, programa/IES e área de conhecimento.

\begin{tabular}{|c|c|c|c|c|c|c|}
\hline $\mathbf{N}$ & Título & Autor (a) & Tipo & Ano & Programa/IES & $\begin{array}{c}\text { Área de } \\
\text { conhecimento }\end{array}$ \\
\hline 1 & $\begin{array}{l}\text { Formação } \\
\text { Administração: Visão em } \\
\text { Práticas Pedagógicas em } \\
\text { Instituições de Ensino } \\
\text { Superior de Excelência do } \\
\text { Rio de Janeiro. }\end{array}$ & $\begin{array}{l}\text { Alexandre } \\
\text { Fernandes } \\
\text { Ferreira }\end{array}$ & Dissertação & 2010 & $\begin{array}{l}\text { PPG - Fundação } \\
\text { Getúlio Vargas - } \\
\text { RJ }\end{array}$ & Administração \\
\hline 2 & $\begin{array}{l}\text { Tornar-se Professor de } \\
\text { Administração: } \text { Um } \\
\text { Estudo sobre o Papel da } \\
\text { Afetividade na Trajetória } \\
\text { Profissional. } \\
\end{array}$ & $\begin{array}{l}\text { Claudia } \\
\text { Cristina da } \\
\text { Rocha } \\
\text { Medrado }\end{array}$ & Dissertação & 2012 & $\begin{array}{l}\text { PPG- Pontifícia } \\
\text { Universidade } \\
\text { Católica de São } \\
\text { Paulo }\end{array}$ & Educação \\
\hline 3 & $\begin{array}{lc}\text { De Profissional e } & \text { e } \\
\text { Profissional- } & \text { Professor: } \\
\text { Contribuições para a } \\
\text { Formação de } & \text { Professores } \\
\text { Universitários da área da } \\
\text { Administração }\end{array}$ & $\begin{array}{l}\text { Luciana } \\
\text { Andréa } \\
\text { Afonso } \\
\text { Sigalla }\end{array}$ & Dissertação & 2012 & $\begin{array}{l}\text { PPG - Pontifícia } \\
\text { Universidade } \\
\text { Católica de São } \\
\text { Paulo. }\end{array}$ & Educação \\
\hline 4 & $\begin{array}{ll}\text { Entre a Macropolítica e a } \\
\text { Micropolítica: } & \text { A } \\
\text { Formação continuada do } \\
\text { Professor do Curso de } \\
\text { Administração. }\end{array}$ & $\begin{array}{l}\text { Ana Paula } \\
\text { Ribeiro de } \\
\text { Faria. }\end{array}$ & Dissertação & 2012 & $\begin{array}{l}\text { PPG - } \\
\text { Universidade } \\
\text { Federal do } \\
\text { Espirito Santo }\end{array}$ & Educação \\
\hline 5 & $\begin{array}{l}\text { Competência Pedagógica } \\
\text { do Docente do Ensino } \\
\text { Superior de Administração } \\
\text { de uma Instituição de } \\
\text { Ensino Superior da Cidade } \\
\text { de Lorena/SP: Um Estudo } \\
\text { de Caso. }\end{array}$ & $\begin{array}{l}\text { Priscila } \\
\text { Rodrigues } \\
\text { de Oliveira } \\
\text { Costa }\end{array}$ & Dissertação & 2013 & $\begin{array}{l}\text { PPG } \\
\text { Universidade de } \\
\text { Taubaté }\end{array}$ & Administração \\
\hline 6 & $\begin{array}{l}\text { A Docência em } \\
\text { Administração e Algumas } \\
\text { Contribuições de Projetos } \\
\text { Educativos. }\end{array}$ & $\begin{array}{l}\text { Elaine } \\
\text { Cristina } \\
\text { Franco de } \\
\text { Godoi }\end{array}$ & Dissertação & 2015 & $\begin{array}{l}\text { PPG- } \\
\text { Universidade } \\
\text { Metodista de } \\
\text { São Paulo }\end{array}$ & Educação \\
\hline 7 & $\begin{array}{l}\text { Desenvolvimento de } \\
\text { Competências Docentes } \\
\text { nos Cursos de graduação } \\
\text { em Administração nas IES } \\
\text { Privadas do Estado do Rio } \\
\text { de Janeiro. }\end{array}$ & $\begin{array}{l}\text { Danielle } \\
\text { Almeida } \\
\text { de Oliveira }\end{array}$ & Dissertação & 2016 & $\begin{array}{l}\text { PPG } \\
\text { Universidade do } \\
\text { Grande Rio }\end{array}$ & Administração \\
\hline 8 & $\begin{array}{l}\text { Formação Continuada e } \\
\text { Desenvolvimento } \\
\text { Profissional dos Docentes } \\
\text { de Administração. }\end{array}$ & $\begin{array}{l}\text { Vitor } \\
\text { Rafael } \\
\text { Laurencian } \\
\text { o Aguiar } \\
\end{array}$ & Tese & 2012 & $\begin{array}{l}\text { PPG - Pontifícia } \\
\text { Universidade } \\
\text { Católica de São } \\
\text { Paulo. }\end{array}$ & Educação \\
\hline 9 & A Formação & Amanda & Tese & 2014 & PPG & Administração \\
\hline
\end{tabular}


ISSN 2525-3409 (CC BY 4.0)

\begin{tabular}{|l|l|l|l|l|l|l|}
\hline $\begin{array}{l}\text { Professores para o Ensino } \\
\text { de Administração Baseado } \\
\text { em Competências: } \\
\text { Possibilidades e Desafios }\end{array}$ & $\begin{array}{l}\text { Ribeiro } \\
\text { Vieira }\end{array}$ & & & $\begin{array}{l}\text { Universidade do } \\
\text { Grande Rio }\end{array}$ & \\
& & & & \\
\hline
\end{tabular}

Fonte: os autores

Para a terceira busca, foi realizado um mapeamento das produções científicas publicadas em alguns dos principais periódicos com estratificação na plataforma WebQualis como A1, A2 e B1, Classificação de Periódicos Quadriênio 2013-2016, nas áreas de Administração Pública e de Empresas/ Ciências Contábeis/ Turismo e que possuem também na área de Ensino, abrangendo o intervalo de busca de 2010 a 2016. A busca ocorreu no mês de julho de 2016 quando então, foram selecionadas somente revistas em língua portuguesa, com foco na formação docente na Área da Administração.

O Quadro 4 traz uma síntese dos resultados da pesquisa realizada nas 11 revistas selecionadas da plataforma WebQualis nos últimos sete anos e, que tratam da formação docente do professor de Administração.

Quadro 4 - Mapeamento da quantidade de artigos revisados e selecionados por periódico.

\begin{tabular}{|c|c|c|c|c|c|}
\hline Periódico & $\begin{array}{l}\text { Qualis na área } \\
\text { de } \\
\text { Administração }\end{array}$ & ISSN & $\begin{array}{c}\text { Período do } \\
\text { levantamento }\end{array}$ & $\begin{array}{c}\text { Total de } \\
\text { artigos } \\
\text { pesquisados }\end{array}$ & $\begin{array}{c}\text { Total de } \\
\text { artigos que } \\
\text { abordavam a } \\
\text { temática }\end{array}$ \\
\hline $\begin{array}{c}\text { Cadernos EBAPE.BR } \\
\text { (FGV. Online) }\end{array}$ & $\mathrm{A} 2$ & $1679-3951$ & 2010 a 2016 & 176 & 2 \\
\hline $\begin{array}{c}\text { Rac. Revista de } \\
\text { Administração } \\
\text { Contemporânea (Online). }\end{array}$ & $\mathrm{A} 2$ & $1982-7849$ & 2010 a 2016 & 310 & 0 \\
\hline RAE (Online) & $\mathrm{A} 2$ & $2178-938 X$ & 2010 a 2016 & 207 & 0 \\
\hline $\begin{array}{c}\text { Revista De } \\
\text { Administração (São } \\
\text { Paulo. Online) }\end{array}$ & $\mathrm{A} 2$ & $1984-6142$ & 2010 a 2016 & 228 & 1 \\
\hline $\begin{array}{l}\text { Base (São Leopoldo. } \\
\text { Online) }\end{array}$ & B1 & 1984-8196 & 2010 a 2016 & 179 & 0 \\
\hline $\begin{array}{l}\text { Cadernos De Pesquisa } \\
\text { (Fundação Carlos } \\
\text { Chagas. Online) }\end{array}$ & B1 & $1980-5314$ & 2010 a 2016 & 309 & 0 \\
\hline Educação e Pesquisa & B1 & $1678-4634$ & 2010 a 2016 & 363 & 0 \\
\hline $\begin{array}{l}\text { Revista de Ciências da } \\
\text { Administração }\end{array}$ & B1 & $2175-8077$ & 2010 a 2016 & 253 & 1 \\
\hline $\begin{array}{l}\text { Revista Eletrônica de } \\
\text { Administração }\end{array}$ & B1 & $1980-4164$ & 2010 a 2016 & 200 & 1 \\
\hline $\begin{array}{c}\text { Revista Eletrônica } \\
\text { Educare }\end{array}$ & B1 & $1409-4258$ & 2010 a 2016 & 346 & 1 \\
\hline $\begin{array}{c}\text { Revista de } \\
\text { Administração } \\
\text { Mackenzie } \\
\end{array}$ & B1 & $1678-6971$ & 2010 a 2016 & 313 & 0 \\
\hline \multicolumn{4}{|c|}{ Total geral de artigos } & 2.884 & 6 \\
\hline
\end{tabular}

Fonte: os autores 
Uma leitura e análise visual detalhada dos títulos dos artigos (um a um) listados no sumário das publicações das revistas nos últimos sete anos, desencadeou o processo de exclusão, no intuito de suprimir os trabalhos que não tratavam da Formação docente do professor de Administração e, concomitantemente, identificar e resgatar trabalhos que abordavam a temática para posterior leitura e análise.

O Quadro 5, apresenta os resultados da pesquisa dos artigos publicados nas 11 revistas selecionadas, sendo que dos 2.884 artigos encontrados e analisados, somente 6 deles tratavam da formação docente do professor de Administração, revelando o baixo número de publicações com a temática, nesse banco de dados.

\section{Quadro 5 - Artigos publicados por periódico, volume, número, ano, autores e título.}

\begin{tabular}{|c|c|c|c|}
\hline Periódico & $\begin{array}{l}\text { Vol./Num. } \\
\text { /Ano }\end{array}$ & Autores & Título \\
\hline \multirow[t]{2}{*}{$\begin{array}{l}\text { Cadernos } \\
\text { EBAPE.BR (FGV. } \\
\text { Online) }\end{array}$} & $14 / 4 / 2014$ & $\begin{array}{l}\text { Danilo Melo } \\
\text { Maurício Serva }\end{array}$ & $\begin{array}{l}\text { A agenda do professor-pesquisador } \\
\text { Administração: uma análise baseada } \\
\text { sociologia da ciência. }\end{array}$ \\
\hline & $12 / 3 / 2016$ & $\begin{array}{l}\text { Marcos Vinícius Pereira } \\
\text { Correa } \\
\text { Mariane Lemos } \\
\text { Lourenço }\end{array}$ & $\begin{array}{l}\text { A constituição da identidade dos professores } \\
\text { de pós-graduação stricto sensu em duas } \\
\text { instituições de ensino superior: um estudo } \\
\text { baseado nas relações de poder e papéis em } \\
\text { organizações }\end{array}$ \\
\hline $\begin{array}{c}\text { Revista de } \\
\text { Administração (São } \\
\text { Paulo. Online) }\end{array}$ & $48 / 4 / 2013$ & $\begin{array}{l}\text { Marcos Roberto Kuhl, } \\
\text { Marlete Beatriz } \\
\text { Maçaneiro, João Carlos } \\
\text { da Cunha e Sieglinde } \\
\text { Kindl da Cunha }\end{array}$ & $\begin{array}{l}\text { O valor das competências docentes no ensino } \\
\text { da Administração }\end{array}$ \\
\hline $\begin{array}{l}\text { Revista de Ciências } \\
\text { da Administração }\end{array}$ & $18 / 45 / 2016$ & $\begin{array}{c}\text { Maurício Serva, Daniel } \\
\text { Moraes Pinheiro, Danilo } \\
\text { Melo, Gustavo } \\
\text { Matarazzo }\end{array}$ & $\begin{array}{lcccc}\text { Lógicas de ação } & \text { de professores } & \text { em } \\
\text { administração: uma } & \text { análise baseada } & \text { na } \\
\text { sociologia da ciência } & & & \end{array}$ \\
\hline $\begin{array}{l}\text { Revista Eletrônica de } \\
\text { Administração }\end{array}$ & $19 / 2 / 2013$ & $\begin{array}{c}\text { Luiz Cláudio Vieira de } \\
\text { Oliveira, Zélia Miranda } \\
\text { Kilimnik, Rafael Parreira } \\
\text { de Oliveira }\end{array}$ & $\begin{array}{l}\text { Da gerência para a docência: metáforas do } \\
\text { discurso de transição. }\end{array}$ \\
\hline $\begin{array}{l}\text { Revista Eletrônica } \\
\text { Educare }\end{array}$ & $16 / 2 / 2012$ & $\begin{array}{l}\text { Maria Isabel Araya } \\
\text { Muñoz, } \\
\text { Carolina Espanha } \\
\text { Chavarria }\end{array}$ & $\begin{array}{l}\text { Autonomia profissional competência-chave } \\
\text { para professores em educação empresarial }\end{array}$ \\
\hline
\end{tabular}

\section{Fonte: os autores}

A quarta busca, se deu no Portal de Periódicos CAPES/MEC. Foi utilizada a opção de busca avançada de artigos que continham no título as expressões " Formação de professores" e “Administração" e data de publicação "últimos 10 anos". Cinco artigos foram encontrados e apenas um selecionado, por estar em língua portuguesa e no período de 2010 a 2016. 
Research, Society and Development, v. 7, n. 7, p. 01-22, e1177358, 2018

ISSN 2525-3409 (CC BY 4.0)

O Quadro 6 apresenta resumidamente, o resultado da pesquisa no Portal de Periódicos

CAPES/MEC.

Quadro 6 - Artigo publicado em periódico, volume, número, ano, autores e título.

\begin{tabular}{|c|c|c|l|}
\hline Periódico & $\begin{array}{c}\text { Vol./Nu } \\
\text { m./Ano }\end{array}$ & Autores & Título \\
\hline $\begin{array}{c}\text { REGE - } \\
\text { Revista de Gestão }\end{array}$ & 2012 & $\begin{array}{c}\text { Arnaldo José Nogueira } \\
\text { França Mazzei; } \\
\text { Fabrício César Bastos }\end{array}$ & $\begin{array}{l}\text { Formação em Administração: o } \\
\text { gap de competências entre alunos } \\
\text { e professores. }\end{array}$ \\
\hline
\end{tabular}

Fonte: os autores

Os trabalhos selecionados, foram agrupados em duas categorias, em consonância com o preconizado pela ATD, sendo: 1. Processos formativos e a constituição de administradores e 2. Docência em administração e conhecimentos pedagógicos. Após o processo de categorização, os dados foram descritos e interpretados em metatexto (MORAES, GALIAZZI, 2014).

A primeira categoria - Processos formativos e a constituição de administradores professores, (Quadro 7), reúne os estudos que abordam o processo de formação em Administração e de mudança na ação profissional quando administradores se tornam professores.

Quadro 7 - Primeira categoria da revisão

CATEGORIA 1 - Processos formativos e a constituição de Administradores Professores

\begin{tabular}{|c|c|c|c|}
\hline $\mathbf{N}$ & Título & $\begin{array}{l}\text { Tipo de } \\
\text { publicação/ } \\
\text { ano }\end{array}$ & Banco de dados \\
\hline 1 & $\begin{array}{l}\text { Trabalho e formação docente em tempos globais e a } \\
\text { constituição de administradores professores. }\end{array}$ & Dissertação & $\begin{array}{l}\text { Banco de Teses e } \\
\text { Dissertações da CAPES }\end{array}$ \\
\hline 2 & $\begin{array}{l}\text { Dormi profissional, acordei professor: um estudo sobre a } \\
\text { prática pedagógica do docente do curso de administração da } \\
\text { UNIPAR - Paraná/ Brasil. }\end{array}$ & Dissertação & $\begin{array}{l}\text { Banco de Teses e } \\
\text { Dissertações da CAPES }\end{array}$ \\
\hline 3 & $\begin{array}{l}\text { Formação de formadores: uma experiência no curso de } \\
\text { administração na modalidade a distância. }\end{array}$ & Dissertação & $\begin{array}{l}\text { Banco de Teses e } \\
\text { Dissertações da CAPES }\end{array}$ \\
\hline 4 & $\begin{array}{l}\text { Desafios da formação docente: estágio docência e a prática de } \\
\text { ensino em administração. }\end{array}$ & Dissertação & $\begin{array}{l}\text { Banco de Teses e } \\
\text { Dissertações da CAPES }\end{array}$ \\
\hline 5 & Da formação à docência um estudo em IES mineira. & Dissertação & $\begin{array}{l}\text { Banco de Teses e } \\
\text { Dissertações da CAPES }\end{array}$ \\
\hline 6 & $\begin{array}{l}\text { De profissional a profissional professor: contribuições para a } \\
\text { formação de professores universitários da área de } \\
\text { administração. }\end{array}$ & Dissertação & IBICT \\
\hline 7 & Tornar-se professor de administração: um estudo sobre o papel & Dissertação & IBICT \\
\hline
\end{tabular}




\begin{tabular}{|c|c|c|c|}
\hline & da afetividade na trajetória profissional & & \\
\hline 8 & $\begin{array}{l}\text { Desenvolvimento de competências docentes nos cursos de } \\
\text { graduação em administração nas IES privadas do estado do } \\
\text { Rio de Janeiro }\end{array}$ & Dissertação & IBICT \\
\hline 9 & $\begin{array}{l}\text { Entre a macro política e a micropolítica: formação continuada } \\
\text { do professor do curso de administração. }\end{array}$ & Dissertação & IBICT \\
\hline 10 & $\begin{array}{l}\text { A formação em administração: visão e práticas pedagógicas } \\
\text { em instituições de ensino superior de excelência do Rio de } \\
\text { Janeiro. }\end{array}$ & Dissertação & IBICT \\
\hline 11 & $\begin{array}{l}\text { O processo de socialização profissional de professores do } \\
\text { ensino superior atuantes no curso de administração: trajetórias, } \\
\text { saberes e identidades. }\end{array}$ & Tese & $\begin{array}{l}\text { Banco de } \\
\text { Dissertações da CAPES }\end{array}$ \\
\hline 12 & $\begin{array}{l}\text { Formação continuada e desenvolvimento profissional dos } \\
\text { docentes de administração. }\end{array}$ & Tese & IBICT \\
\hline 13 & $\begin{array}{l}\text { A formação de professores para o ensino de administração } \\
\text { baseado em competências: possibilidades e desafios. }\end{array}$ & Tese & IBICT \\
\hline 14 & $\begin{array}{l}\text { Da gerência para a docência: metáforas do discurso de } \\
\text { transição. }\end{array}$ & Artigo & WebQualis \\
\hline 15 & $\begin{array}{l}\text { O valor das competências docentes } \\
\text { Administração. }\end{array}$ & Artigo & WebQualis \\
\hline 16 & $\begin{array}{l}\text { A constituição da identidade dos professores de pós-graduação } \\
\text { stricto sensu em duas instituições de ensino superior: um } \\
\text { estudo baseado nas relações de poder e papéis em } \\
\text { organizações. }\end{array}$ & Artigo & WebQualis \\
\hline 17 & $\begin{array}{l}\text { Autonomia profissional. Competência-chave para professores } \\
\text { em educação empresarial. }\end{array}$ & Artigo & WebQualis \\
\hline 18 & $\begin{array}{l}\text { A agenda do professor-pesquisador em administração: uma } \\
\text { análise baseada na sociologia da ciência. }\end{array}$ & Artigo & WebQualis \\
\hline
\end{tabular}

\section{Fonte: Os autores}

A segunda categoria - Docência em Administração e conhecimentos pedagógicos, (Quadro 8), agrupa as dissertações, teses e artigos que tratam da educação em Administração e as práticas pedagógicas envolvidas no processo de ensino e aprendizagem desta área de conhecimento.

\section{Quadro 8 - Segunda categoria da revisão}

\begin{tabular}{|c|c|c|c|}
\hline \multicolumn{3}{|c|}{ CATEGORIA 2 - Docência em Administração e as práticas pedagógicas } & \multirow[b]{2}{*}{ Banco de dados } \\
\hline & Título & $\begin{array}{r}\text { Tip } \\
\text { publi }\end{array}$ & \\
\hline 1 & $\begin{array}{l}\text { Mapeamento de competências docentes: estudo entre } \\
\text { dêmicos de administração. }\end{array}$ & Dissertação & $\begin{array}{l}\text { Banco de Teses e } \\
\text { Dissertações da CAPES }\end{array}$ \\
\hline 2 & $\begin{array}{l}\text { Competências profissionais do professor do ensino } \\
\text { superior para lecionar administração, pós-graduação lato } \\
\text { sensu, na EaD online: um estudo em IES da região } \\
\text { metropolitana do Recife. }\end{array}$ & 10 & $\begin{array}{l}\text { Banco de Teses e } \\
\text { Dissertações da CAPES }\end{array}$ \\
\hline 3 & $\begin{array}{l}\text { Formação docente e } \text { inovações tecnológicas } \\
\text { informação e comunicação: um estudo de caso em } \\
\text { administração. }\end{array}$ & Diss & $\begin{array}{l}\text { Banco de Teses e } \\
\text { Dissertações da CAPES }\end{array}$ \\
\hline 4 & $\begin{array}{l}\text { Professor universitário dos cursos de administração e } \\
\text { ciências contábeis: saberes e práticas. }\end{array}$ & Diss & $\begin{array}{l}\text { Banco de } \quad \text { Teses } \mathrm{e} \\
\text { Dissertações da CAPES }\end{array}$ \\
\hline 5 & $\begin{array}{l}\text { A inserção da noção de competências na prática } \\
\text { docente: um estudo em curso de graduação em administração }\end{array}$ & Dissertação & $\begin{array}{l}\text { Banco de Teses e } \\
\text { Dissertações da CAPES }\end{array}$ \\
\hline
\end{tabular}




\begin{tabular}{|c|c|c|c|}
\hline 6 & $\begin{array}{l}\text { Concepções de ensino, aprendizagem e administração } \\
\text { em projetos pedagógicos de cursos de administração em Goiás }\end{array}$ & Dissertação & $\begin{array}{l}\text { Banco de Teses e } \\
\text { Dissertações da CAPES }\end{array}$ \\
\hline 7 & $\begin{array}{l}\text { Narrativas sobre prática pedagógica e desenvolvimento } \\
\text { profissional: administradores-professores de ensino superior } \\
\text { como protagonistas. }\end{array}$ & Dissertação & $\begin{array}{l}\text { Banco de Teses e } \\
\text { Dissertações da CAPES }\end{array}$ \\
\hline 8 & $\begin{array}{l}\text { Demandas e competências nas práticas docentes no } \\
\text { curso de administração de empresas - bacharelado. }\end{array}$ & $\mathrm{Di}$ & $\begin{array}{l}\text { Banco de Teses e } \\
\text { Dissertações da CAPES }\end{array}$ \\
\hline 9 & $\begin{array}{l}\text { A formação em administração: a visão e as práticas } \\
\text { edagógicas em IES de excelência do Rio de Janeiro }\end{array}$ & $\mathrm{D}$ & $\begin{array}{l}\text { Banco de Teses e } \\
\text { Dissertações da CAPES }\end{array}$ \\
\hline 10 & $\begin{array}{l}\text { Competênc } \\
\text { administraç } \\
\text { de Lorena- }\end{array}$ & o & IBICT \\
\hline 1 & $\begin{array}{l}\text { cia em administração e algumas contribuições } \\
\text { cativos. }\end{array}$ & rtação $^{\text {Dis }}$ & IBICT \\
\hline 12 & $\begin{array}{l}\text { Os saberes docentes construídos pelos professores e as } \\
\text { práticas de ensino no curso superior de administração da } \\
\text { FCAP/UPE }\end{array}$ & Tese & $\begin{array}{l}\text { Banco de Teses e } \\
\text { Dissertações da CAPES }\end{array}$ \\
\hline 13 & $\begin{array}{l}\text { Gestão eficiente em sala de aula: seis estudos em } \\
\text { ciências sociais aplicadas }\end{array}$ & Tes & $\begin{array}{l}\text { Banco de Teses e } \\
\text { Dissertações da CAPES }\end{array}$ \\
\hline 14 & $\begin{array}{l}\text { Lógicas de ação de professores em administração: uma } \\
\text { análise baseada na sociologia da ciência. }\end{array}$ & Artigo & WebQualis \\
\hline 15 & $\begin{array}{l}\text { Formação em administração: } \\
\text { alunos e professores. }\end{array}$ & $\mathrm{A}$ & $\begin{array}{l}\text { Portal de } \\
\text { CAPES }\end{array}$ \\
\hline
\end{tabular}

Fonte: os autores

\section{Metatexto - síntese dos dados categorizados}

Integram a categoria 1. Processos formativos e a constituição de administradores professores, 10 dissertações, 3 teses e 5 artigos científicos que buscam responder as questões: Como se dá a formação pedagógica do professor da Educação Superior de Administração? Quais são as abordagens pedagógicas que fundamentam a educação em Administração? e, por conseguinte, deram origem as unidades de análise.

Buscando respostas a essas questões, estudos de Silva (2012), Torres (2010) e Cunha (2012), apontam que a formação docente para os profissionais administradores é negligenciada na sua graduação, pois há omissão de sua formação pedagógica o que afeta a qualidade do ensino na educação superior. Apontam também, a falta de políticas de formação continuada para aperfeiçoamento das práticas docentes e a necessidade de uma formação docente para o administrador que atua no ensino frente as demandas do Ensino Superior de Administração no Brasil.

Nesse sentido, Valdisser (2012) indica que, os profissionais atuantes no ensino de Administração têm sido obrigados a se capacitarem de forma que possam adquirir e utilizar adequadamente as competências necessárias no processo de formação de docentes. Isso, para que possam empregar metodologias de ensino que contribuam para a melhoria do ensino de Administração. $\mathrm{O}$ autor resgata que, apesar de contribuírem para a formação e 
desenvolvimento de competências, os programas de pós-graduação na área da Administração, ainda precisam priorizar mais a formação e o desenvolvimento de competências relacionadas a atuação docente.

Considerando essa realidade, Joaquim (2013) identifica o estágio docência nos cursos de pós-graduação como uma alternativa metodológica e prática pedagógica eficiente para a formação de professores administradores mais bem preparados para a docência.

Pesquisa de Takeda (2011) também considera as necessidades formativas do Administrador para a docência e destaca que os professores do curso de Administração atuam na docência a partir de seu conhecimento técnico-profissional enquanto administrador e que, seu planejamento docente é embasado nas necessidades de desempenho profissional específico, tendo como elemento estruturante da sua atuação didática a reprodução das informações listadas na ementa ou programa da disciplina que leciona.

Os resultados dos estudos destacados nessa categoria são amparados por Pimenta e Anastasiou (2005), quando afirmam que os professores de Ensino Superior adentram a sala de aula sem o devido preparo e sua prática didática se limita, muitas vezes, a imitar determinado professor por considera-lo um bom modelo.

Por sua vez, na categoria 2 - Docência em Administração e as práticas pedagógicas estão 11 dissertações, 2 teses e 1 artigo, por apresentarem em seus títulos, palavras relacionadas ao trabalho docente, ao processo de ensino e à prática pedagógica no ensino de Administração.

As pesquisas selecionadas nessa categoria, abordam questões como: de que forma o bacharel-professor consolida sua prática pedagógica? (CAMPELO, 2011). Quais são as estratégias utilizadas por professores de Administração em sala de aula para estimular e catalisar o interesse dos estudantes e o comprometimento com sua própria formação profissional? (SILVA, 2012). Quais são os critérios sob os quais os professores planejam e executam suas ações pedagógicas? (CONTI, 2010). Destacam também, o papel da didática para a formação docente do administrador nas atividades de ensinar e aprender, além de sugerir a possibilidade de atitude crítica nas práticas cotidianas dos docentes de Administração (CUNHA, 2012).

Dentre os resultados, a pesquisa de Cunha (2012) constata que a menção a metodologia de ensino existente hoje no ensino de Administração se restringe a utilização de algumas técnicas, não havendo outras referências mais claras quanto a metodologia utilizada. Já em relação a avaliação da aprendizagem, ocorre por meio de avaliação formativa com enfoque na dimensão quantitativa e somatória de notas. Tal prática indica uma concepção 
tradicional e mecanicista de ensino e de aprendizagem, não condizente com a formação de um profissional mais humanista e transformador indicada como objetivo dos Cursos de Graduação em Administração (CUNHA, 2012).

Quanto às concepções de ensino e aprendizagem que constam na maioria dos projetos pedagógicos analisados na pesquisa de Cunha (2012), essas ainda se encontram presas a metodologias de ensino como meras técnicas de administrar as aulas e de uma aprendizagem como memorização e repetição de conteúdos.

Campelo (2011) considera que os professores de Administração, apesar de não terem seguido uma formação própria para o magistério, são profissionais que conseguiram demonstrar grande multiplicidade de saberes durante a realização do trabalho docente. Destaca que os docentes realizam aulas expositivas, trabalhos em equipe, estudos de casos e com relação a avaliação, utilizam provas escritas, seminários trabalhos de campo e combinações dessas modalidades avaliativas. O autor identificou ainda, que "os professores de Administração demonstram mais desenvoltura nos saberes experienciais, provenientes de atividades profissionais desenvolvidas, muitas vezes em paralelo ao ensino, o que causa preocupação pelo fato de os professores parecerem valorizar mais as experiências práticas do que as bases teóricas das disciplinas" (CAMPELO, 2011, p. 267).

Costa (2013) identifica fatores componentes da competência pedagógica necessária aos docentes do Ensino Superior de Administração, e dentre estes destaca: carreira e desenvolvimento profissional, formação docente e atualização, valores pessoais, condução da aula e preparação da aula. Considera que a formação docente é de extrema importância para o desenvolvimento e constituição do professor de Administração e evidencia a valorização por parte dos professores, de uma formação pedagógica continuada que se apresenta como uma alternativa para a melhoria da prática docente.

Outro estudo relevante para esta pesquisa é de autoria de Aguiar (2012), o qual salienta que os professores da graduação em Administração são diferentes dos professores profissionais da licenciatura, e a falta dos saberes pedagógicos sugere que recorram aos seus modelos de bons professores o que, nem sempre, resulta em um ensino de qualidade. No entanto, pela falta dos saberes docentes, seus saberes experienciais, provenientes do trabalho profissional na área administrativa, muitas vezes exercido em paralelo ao ensino, são fundamentais e servem de modelo para sua prática docente pelo fato de o curso de Administração ter ligação direta com o mercado de trabalho, sendo sua função formar o trabalhador que o mercado necessita. Os saberes provenientes dos programas e livros 
didáticos parecem então, ser secundarizados pelos professores da graduação em Administração.

Nesse sentido, Aguiar (2012) destaca que sendo considerados diferentes, os professores de Administração devem ter uma formação continuada também diferenciada, pois são outras as suas necessidades e a sua relação com o trabalho docente. Nesse sentido, Silva (2012) destaca que dada a formação do professor de Administração e, consequentemente, o seu pragmatismo, são solicitadas mais práticas, mais dinâmicas, mais envolvimento nos cursos de formação continuada.

Todas as pesquisas relacionadas nessa categoria, apontam a necessidade que os professores de Administração têm de se capacitar para aquisição e utilização adequadas das competências inerentes ao trabalho docente, no intuito de aprimorar suas práticas e desenvolver ferramentas para uso em sala de aula.

\section{Considerações finais}

Foi possível depreender que, para o professor de Administração não bastam a experiência e os conhecimentos específicos da área da Administração. São necessários também os saberes pedagógicos e didáticos adequados, maior reflexão e mais pesquisas, assim como, seleção cuidadosa de recursos/produtos educacionais, métodos e estratégias para utilização em sala de aula.

Os estudos enquadrados na categoria 1, indicam que grande parte dos conteúdos dos cursos de Graduação em Administração no Brasil, configuram-se ainda, em uma dimensão funcionalista, alguns sem efetividade ou pouca contribuição com os egressos quanto á formação para a docência, indicam também, a falta de políticas de formação continuada para aperfeiçoamento das práticas docentes.

Em geral, os administradores que atuam na docência, o fazem a partir de seu conhecimento técnico-profissional, e seu planejamento docente, muitas vezes, é embasado na reprodução das informações listadas na ementa ou programa da disciplina que leciona. Por isso necessitam se capacitar, de forma que possam adquirir e utilizar adequadamente as competências necessárias ao trabalho docente.

Por sua vez, as pesquisas relacionadas na categoria 2, indicam que as pesquisas analisadas indicam que alguns administradores-professores consolidam sua prática pedagógica não utilizando metodologias de ensino, mas algumas técnicas, sem que haja referências mais claras quanto á metodologia utilizada. As estratégias utilizadas por eles em sala de aula, para estimular e catalisar o interesse dos estudantes, e o comprometimento com 
sua própria formação profissional, se dão, por meio de uma concepção tradicional e mecanicista de ensino e de aprendizagem, não condizente com a formação de um profissional mais humanista e transformador indicada, como objetivam os cursos de Administração.

Os critérios sob os quais os professores planejam e executam suas ações pedagógicas, ainda se encontram presos a metodologias de ensino como meras técnicas de administrar as aulas e de uma aprendizagem como memorização e repetição de conteúdos. Porém, apesar de não terem seguido uma formação própria para o magistério, empregam uma multiplicidade de saberes durante a realização do trabalho docente, com mais desenvoltura nos saberes experienciais, provenientes de atividades profissionais desenvolvidas de forma paralela ao ensino.

Pelas características citadas acima, os professores da Graduação em Administração são considerados diferentes dos professores com formação em licenciatura. Isso, possivelmente ocorra devido a sua formação e ao seu pragmatismo, o que reforça a necessidade de uma formação continuada, mas diferenciada para o trabalho docente, por envolver mais atividades práticas e dinâmicas.

Diante disso, considera-se que a formação docente é de extrema importância para o desenvolvimento e constituição do professor de Administração e, evidencia-se a valorização por parte dos professores, de uma formação pedagógica continuada que se apresenta como uma alternativa para a melhoria da prática docente nos cursos de Administração.

Sendo assim, os resultados sugerem o desenvolvimento de trabalhos futuros, com oferta de cursos de Formação Pedagógica para professores de Administração, com foco nos saberes docentes, nas abordagens metodológicas de ensino mais inovadoras, tipos e instrumentos de avaliação mais adequados, assim como, formas de utilização de Tecnologias Digitais de Informação e Comunicação (TDIC). O objetivo seria canalizar e motivar a atenção dos alunos para os conteúdos ministrados em sala de aula. Tais iniciativas, poderão melhor instrumentalizar os administradores para atuarem na docência e também contribuir, consequentemente, com formação de um profissional mais competente e preparado.

\section{Referências}

AGUIAR, Vitor Rafael Laurenciano. Formação Continuada e Desenvolvimento Profissional dos Docentes de Administração. 2012. 130f. Tese (Doutorado em Educação) Pontifícia Universidade Católica de São Paulo. São Paulo, 2012.

BRASIL. Banco de Teses e Dissertações da Coordenação de Aperfeiçoamento de Pessoal de Nível Superior -CAPES. Disponível em

http://bancodeteses.capes.gov.br/banco-teses/\#/ Acesso em: 11 maio 2017. 
Diretrizes Curriculares Nacionais para o curso de Graduação em Administração. Resolução do Conselho Nacional de Educação no 4 de 13 de julho de 2005:Conselho Nacional de Educação/Câmara de Educação Superior. Disponível em http://portal.mec.gov.br/cne/arquivos/pdf/rces004_05.pdf Acesso em: 11 maio 2017.

.Lei n.9394, de 20 de dezembro de 1996. Estabelece as diretrizes e bases da educação nacional. Brasília, DF, 1996.

Critérios para autorização e reconhecimento de cursos de Instituições de Ensino Superior. Parecer do Conselho Nacional da Educação no 1070 de 1999: Ministério da Educação. Disponível em http://portal.mec.gov.br/cne/arquivos/pdf/1999/pces1070_99.pdf Acesso em: 11 maio 2017.

CAMPELO, Arandi Maciel. Os saberes docentes construídos pelos professores e as práticas de ensino no Curso Superior de Administração da FCAP/UPE. 2011287 f. Tese (Doutorado em Educação) - Universidade Federal de Pernambuco, Recife, 2011.

CONSELHO FEDERAL DE ADMINISTRAÇÃO. Resolução Normativa no 301 de 10 de janeiro de 2005. Dispõe sobre o registro profissional de Professor que leciona matérias técnicas dos campos da Administração. Brasília, 2005

CONTI, Sergio Luiz. Demandas e competências nas práticas docentes no curso de Administração de Empresas - Bacharelado. 2010 178f. Dissertação (Mestrado em Educação) - Universidade Cidade de São Paulo, São Paulo, 2010.

CORREA, Marcos Vinícius Pereira; LORENÇO, Mariane Lemos. A constituição da identidade dos professores de pós-graduação stricto sensu em duas instituições de ensino superior: um estudo baseado nas relações de poder e papéis em organizações. Cadernos EBAPE.BR , Rio de Janeiro, v.14, n. 4, p. 858 - 871, Out./Dez.2016

COSTA, Priscila Rodrigues Oliveira. Competência Pedagógica do Docente do Ensino Superior de Administração de uma Instituição de Ensino Superior da Cidade de Lorena/SP : Um Estudo de Caso. 2013 83f. Dissertação (Mestrado em Administração) Universidade de Taubaté, Taubaté, 2013.

CUNHA, Jhonny Afonso. Concepções de ensino, aprendizagem e administração em projetos pedagógicos de cursos de Administração em Goiás. 201284 f. Dissertação (Mestrado em Educação) - Pontifícia Universidade Católica de Goiás, Goiânia, 2012.

CUNHA, Marciano de Almeida. O processo de socialização profissional de professores do ensino superior atuantes no curso de administração: trajetórias, saberes e identidades. 2011225 f. Tese (Doutorado em Educação: História, Política, Sociedade) - Pontifícia Universidade Católica de São Paulo, São Paulo, 2011.

DELIZOICOV, Demétrio; ANGOTTI, José André; PERNAMBUCO, Marta Maria. Ensino de Ciências: fundamentos e métodos. São Paulo: Cortez, 2002. 
FARIA, Ana Paula Ribeiro. Entre a Macropolítica e a Micropolítica : Formação

Continuada do Professor do Curso de Administração. 2012. 153f. Dissertação (Mestrado em Educação) - Universidade Federal do Espírito Santo, 2012.

FERREIRA, Alexandre Fernandes. A Formação em Administração: A Visão e as Práticas Pedagógicas em IES de Excelência do Rio de Janeiro. 2010251 f. Dissertação (Mestrado em Administração) - Fundação Getúlio Vargas, Rio de Janeiro, 2010.

FERREIRA, Thais Rúbia. Formação docente e inovações tecnológicas de informação e comunicação: um estudo do curso de Administração. 2012.103 f. Dissertação (Mestrado em Educação) - Universidade do Oeste Paulista, Presidente Prudente, 2012.

FORTE, Vanessa de Carvalho. Formação de Formadores: Uma experiência no curso de Administração na modalidade a distância. 201091 f. Dissertação (Mestrado em Educação) Universidade Estadual do Ceará, Fortaleza, 2010.

GODOI, Elaine Cristina Franco de. A Docência em Administração e algumas contribuições de projetos educativos. 2015 170f. Dissertação (Mestrado em Educação) Universidade Metodista de São Paulo, 2015.

HAZOFF, Waldemar Júnior; Gestão eficiênte em sala de aula: seis estudos em ciências sociais aplicadas. 2012.167f. Tese (Doutorado em Administração) - Universidade de São Paulo. São Paulo, 2012.

JOAQUIN, Nathália de Fátima. Desafios da formação docente: Estágio Docência e a prática de ensino em administração. 2011198 f. Dissertação (Mestrado em Administração) Universidade Federal de Lavras, Lavras, 2011.

KITCHENHAM. B. Procedures for Performing Systematic Reviews. Keele UK Keele University- Publisher: Citesser, 33(TR/SE-0401), p.28, 2004.

KUHL, Marcos Roberto; MAÇANEIRO, Marlene Beatriz; CUNHA, João Carlos; CUNHA, Sieglinde Kindl da. O valor das competências docentes no ensino da Administração. Revista de Administração, v. 48, nº 4, p. 783-799, Out./Nov./Dez, 2013.

MASEI, Arnaldo José Nogueira França; BASTOS, Fabricio Cezar. Formação em Administração: o gap de competências entre alunos e professores. REGE Revista de Gestão. v.19, no2, p.223-239, abril/jun./1012.

MEDRADO, Claudia Cristina da Rocha, Tornar-se Professor de Administração: Um estudo sobre o papel da afetividade na trajetória profissional. 2012. 160f. Dissertação (Mestrado em Educação) Pontifícia Universidade Católica de São Paulo, São Paulo, 2012.

MELO, Danilo; SERVA, Mauricio. A agenda do professor-pesquisador em Administração: uma análise baseada na sociologia da ciência. Cadernos EBAPE.BR, Rio de Janeiro, v.12, n. 3, p. $605-632$, jul./set.2014.

MELO, Rita de Cássia Braga de; Competências Profissionais do professor do ensino superior para lecionar Administração, pós Graduação lato sensu, na EAD on line: um estudo em IES da Região Metropolitana do Recife. 2012. 181f. Dissertação (Mestrado em 
Administração) - Universidade Federal de Pernambuco, Pernambuco, 2012.

MORAES, Roque; GALIAZZI, Maria do Carmo. Análise textual discursiva. UNIJUÍ: 2007.

MUNHOZ, Maria Isabel Araya, CHAVARRIA, Carolina Espanha. Autonomia profissional competência-chave para professores em educação empresarial. Revista Eletrônica Educare. v. 16, no 2, p. 163-170, Mai./Ago./2012.

OLIVEIRA, Danielle Almeida; Desenvolvimento de Competências Docentes nos Cursos de Graduação em Administração nas IES Privadas do Estado do Rio de Janeiro. 2016. Dissertação ( Mestrado em Administração) - Universidade do Grande Rio, Rio de Janeiro, 2016.

OLIVEIRA, Fatima Bayama de; SAUERBRONN, Fernanda Filgueiras. Trajetória, desafios e tendências no ensino superior de administração e administração pública no Brasil: uma breve contribuição. Revista de Administração Pública, Ed. especial comemorativa, v. 41, n.138, p. 149-170. 2007.

OLIVEIRA, Luiz Cláudio Vieira; KILIMNIK, Zelia Miranda; OLIVEIRA, Rafael Pereira de. Da Gerencia para a Docência: Metáforas Do Discurso de Transição. Revista Eletrônica de Administração. v. 19, no 2, p.301- 329, Mai./Ago./2013.

PIMENTA, Selma Garrido; ANASTASIOU, Léa das Graças Camargos. Docência no Ensino Superior. 2 ed. São Paulo: Cortez, 2005.

RAMOS, Marcio Sampedro. Mapeamento de competências docentes: Estudo entre acadêmicos de Administração. 2011146 f. Dissertação (Mestrado em Administração) Universidade Federal de Santa Maria, Santa Maria, 2011.

SARAIVA, Shirlei Dourado Rebêlo. Narrativas sobre Prática Pedagógica e desenvolvimento profissional: Administradores-professores de ensino superior como protagonistas. 2010124 f. Dissertação (Mestrado em Educação) - Fundação Universidade Federal do Piauí, Teresina, 2010.

SERVA, Maurício; PINHEIRO, Daniel Moraes; MELO, Danilo; MATARAZZO, Gustavo. Lógicas de ação de professores em administração: uma análise baseada na sociologia da ciência. Revista de Ciências da Administração. v. 18, no 45, p. 64 -78, Ago./2016

SIGALA, Luciana Andréia Afonso; De profissional a profissional- professor: Contribuições para a formação de professores universitários da área de Administração. 2012. Dissertação (Mestrado em Educação) - Pontifícia Universidade Católica de São Paulo, 2012.

SILVA, Geraldo Rodrigues da; Professor Universitário dos Cursos de Administração e Ciências Contábeis: Saberes e Práticas. 2012133 f. Dissertação (Mestrado em Educação) Universidade Católica de Santos, Santos, 2012.

SIQUEIRA, Laci. A Inserção da noção de competências na prática docente: um estudo em curso de graduação em Administração. 2011123 f. Dissertação (Profissionalizante em Administração) - Pontifícia Universidade Católica de Minas Gerais, Belo Horizonte, 2011

SOARES, Caio Gabriel da Silva; SANTOS, Giovani dos; GREÓRIO, Sidnei Albino; BONFIN, Evandro Luiz Soares; VASCONCELOS, Cláudio Cordeiro. Formação pedagógica 
para que o administrador atue em carreira docente. E-FACEQ: revista dos discentes da Faculdade Eça de Queiroz, ISSN 2238-8605, v. 4, n. 5, mai. 2015.

TAKEDA, Sirlene Aparecida. A. Dormi Profissional, Acordei Professor: um Estudo sobre a Prática Pedagógica do Docente do Curso de Administração da UNIPAR - Paraná/ Brasil. 2011140 f. Dissertação ( Mestrado em Educação) - Universidade do Sul de Santa Catarina, 2011.

TARDIF, Maurice. Saberes Docentes e Formação Profissional. 17.ed. Petrópolis: Vozes, 2014.

TORRES, Valéria Araújo. Trabalho e formação docente em tempos globais e a constituição de administradores professores.2010. 179f. Dissertação (Mestrado em Educação) - Universidade de Uberaba. Uberaba, 2010.

VALDISSER, Cássio Raimundo. Da formação á Docência: um estudo em IES mineiras. 2012. 163f. Dissertação (Mestrado em Administração) - Universidade Federal de Uberlândia. Uberlândia. 2012.

VIEIRA, Amanda Ribeiro. A formação de professores para o ensino de Administração baseado em competências: possibilidades e desafios. 2014. 362p. Tese (Doutorado em Administração) - Faculdade de Economia , Administração e Contabilidade de Ribeirão Preto/USP. Ribeirão Preto,2014. 